\title{
Critical success factors for build-operate- transfer (BOT) projects in China
}

Research Article

\author{
Jiaju Yang ${ }^{1}$, Tahir M Nisar² and Guru Prakash Prabhakar** \\ 'University of Bristol, UK \\ 2University of Southampton, UK \\ ${ }^{3}$ Bristol Business School, University of the West of England, UK
}

\begin{abstract}
This study aims to create a list of CSFs for China's BOT projects to help organizations achieve project success. We first describe the role of CSFs in terms of three broad categories of whether BOT projects adopt strategies for risk transfer, the degree to which BOT projects foster the 'whole- life approach' to project design and management and extent to which BOT projects ensure timely delivery and supplies good-quality products and services. Based on an initial CSF list, a questionnaire survey was conducted to identify the relatively important CSFs for BOT projects in China. Our initial assessment shows that the key CSFs corresponded to our defined categories of BOT projects' success factors. We then provide an updated list of CSFs with the top ten factors in ranking analysis. This list of CSFs could play a useful role in the phases of preparing, bidding, constructing, operating and transferring of BOT projects.
\end{abstract}

Keywords: critical success factors (CSFs); build-operate-transfer (BOT) projects; China

(C) De Gruyter Open Sp. z 0.0 .

\section{INTRODUCTION}

With the rapid process of industrialisation and globalisation in China, there has been a high demand for largescale infrastructure construction including power stations, transportation facilities, water supply plants and sewage treatment plants. To implement infrastructure projects, it calls for substantial funds, advanced technology and effective management. However, due to insufficient financial resources and lack of relevant experience, the Chinese government is not able to meet the significantly increasing needs in business infrastructure (Qiao et al., 2001). Therefore, a new financing model with private investment was introduced in the 1980s named build-operate-transfer (BOT). In this model, private sector's project involvement is limited to building, operating and transferring a publicly funded project (McCarthy and Tiong, 1991). Since the first BOT project Shajiao B power plant was executed in the city of Shenzhen, BOT model has gradually become one of the most important financing approaches to relieving the government's financial burden and it has exerted a profound influence on the development of China's infrastructure. According to Public Works Financing (1999), since 1985 China has proposed nearly 160 infrastructure concessions with the total investment of $>$ US $\$ 91$ billion. The Chinese government has gradually realised that the BOT model is a sound financing technique for infrastructure projects and it is an effective method to share the technical and financial risks with private sector (Tiong, 1996).

The BOT model is one of the public-private partnership (PPP) models, which is defined as the cooperation between government and private entities to provide public infrastructure products and services (Cheng and Wang, 2009). PPP projects respond to the need for innovative and locally tailored designs, ideas and solutions to problems faced by public authorities at all levels of government in different sectors of the economy. For example, investment under the private finance initiative (PFI), the UK government's PPP programme, now makes up between 10 and $15 \%$ of the government's yearly investment in public services. There are currently about 400 operational PFI projects across England. Each PFI project is undertaken after a business case is made for the efficiencies that can be obtained from PFI funding (NAO, 2000). The strength of a PPP funding proposal rests on its critical success 
factors (CSFs), which in turn govern its design and implementation process. An investigation of these factors is likely to provide a better understanding of the contribution private agents can make to the procurement of public goods and services.

Based on Gidman et al. (1995), a PPP model provides a spectrum of degrees of private participation from no private sector to fully private sector (Figure 1), which contributes to different model options. Additionally, the BOT model has some other variants such as build-own-operate (BOO) and build-own-operate-transfer (BOOT) (Kwak et al., 2009). However, there are some differences between them; the private company usually has the asset ownership in BOO projects, while private company owns the BOOT project in the concession period and must transfer the asset ownership to the government at the end of the concession period (Gatti, 2008). In the BOT model, the government grants a concession to the private sector, and in turn, the private sector is committed to supply funds, design, construct and operate the projects for a certain period of time. In the period of operation, the private sector should pay the debt and profit from the operational revenue at an agreed rate of return. After a specific period of operation, the private sector will transfer the ownership of the entity to the government without any extra charge (Chen and Doloi, 2008).

Figure 1. Spectrum of PPP options (Gidman et al., 1995). PPP = public-private partnership

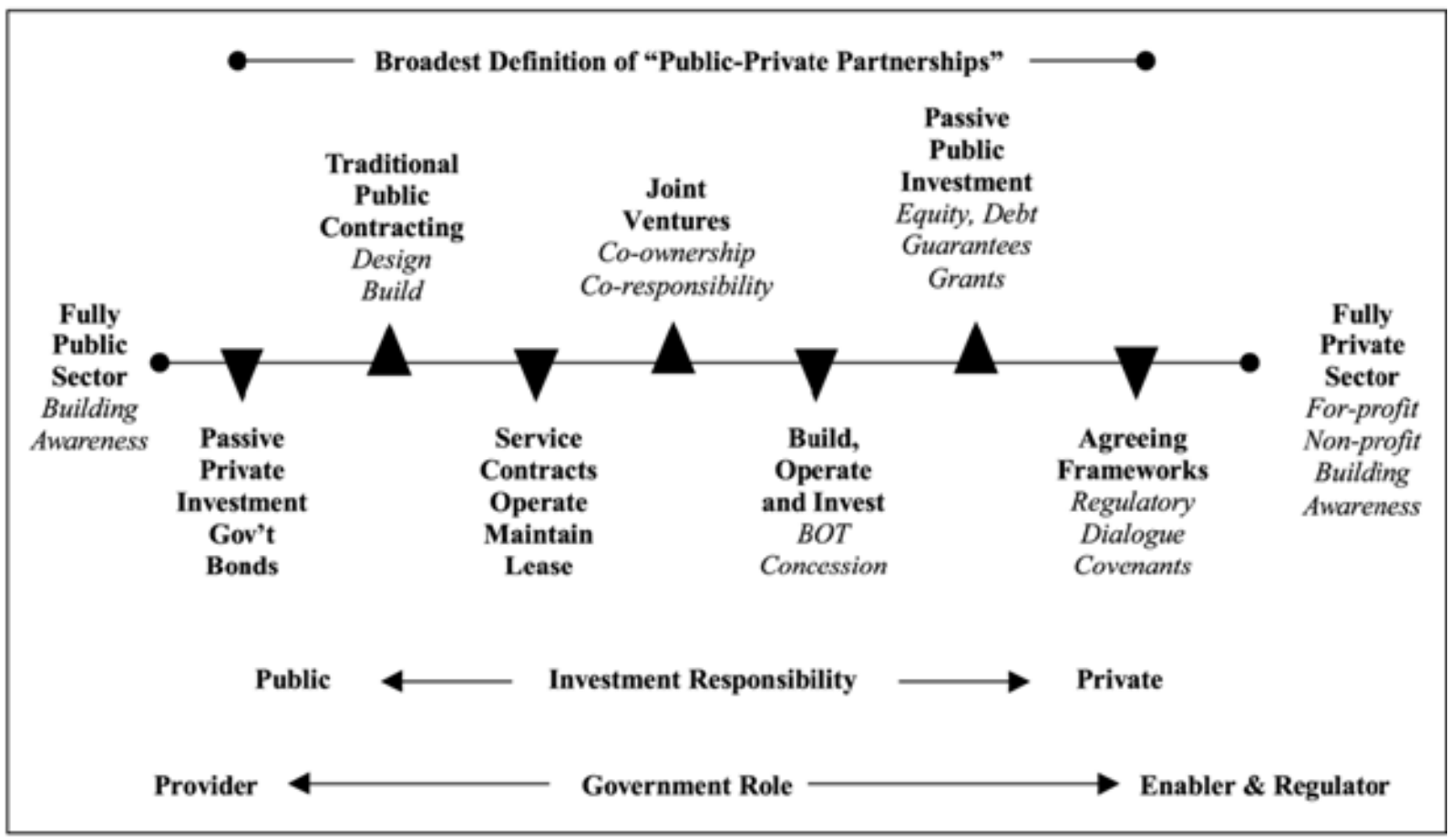

Generally, a typical BOT project involves six main parties including a host government, sponsor(s), lenders, investors, users of product and contractors. However, the host government and sponsor(s) are the two main parties. The host government refers to not only the local government but also the governmental authorities that are engaged in the project, whereas the sponsor refers to consortium, project company or project developer. They come to a concession agreement to determine their equity, responsibility, share, guarantees, etc. Specifically, the host government takes the responsibility of supervising the project, while the project company is responsible for all phases of the project via various contracts with other parties (Figure 2) (Schaufelberger, 2005).

In this research, we advance the idea that there are three broad categories of BOT projects' success factors, including whether BOT projects adopt strategies for risk transfer, the degree to which BOT projects foster the 'wholelife approach' to project design and management and the extent to which BOT projects ensure timely delivery and supply good quality assets and services. This draws on the practice of 'business case' methodological review frameworks that currently governments employ when processing BOT-type projects (HM Treasury, 2010). As there 
are a large number of factors that affect BOT projects' outcome, analysing each one of them separately makes little sense and is not efficient. Therefore, we proposed that CSFs must be considered in terms of their underlying 'business case' rationale and how they are linked up to each other. We conducted a questionnaire survey to identify the relatively important CSFs for BOT projects in China based on an initial CSF list. We found that these CSFs corresponded to our three broad categories of BOT projects' success factors. These categories captured important phases of preparing, bidding, constructing, operating and transferring BOT projects, which can more conveniently be used by project companies and government bodies when making PPP-related decisions. Our research thus builds on the earlier works of Qiao et al. (2001), Li et al. (2005) and Chen and Doloi (2008) who provided initial lists of CSFs. However, in creating these lists, they do not use a more general and coherent criterion in identifying and refining their particular lists of CSFs. For example, Chen and Doloi (2008) relied on the specific features of an institutional environment (e.g. driving factors - needing infrastructure development capital and impeding factors opaque and weak legal systems) to develop their CSFs.

Figure 2. Relationship among BOT projects' participants (Schaufelberger, 2005). BOT = build-operate-transfer

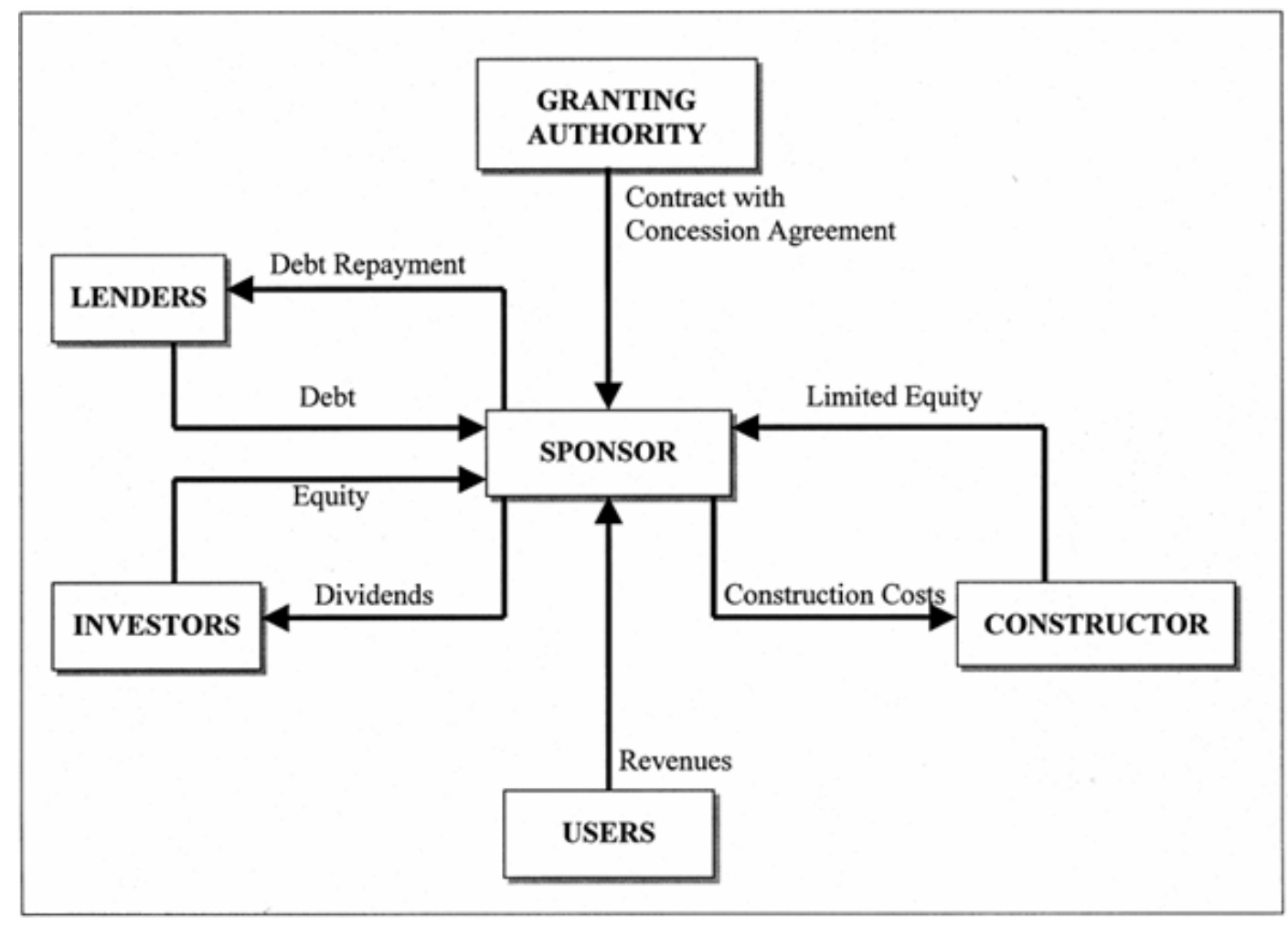

The rest of the paper is organised as follows. We first provide a review of the literature on the role of CSFs in BOT project design and implementation. This is followed by a discussion of our empirical research strategy. We also introduce our data in that section. In the later section, we present our results. The final section concludes with a discussion of the implications of our research and potential areas for future research.

\section{LITERATURE REVIEW}

PPP is essentially an authority-led initiative that encourages commercial investment in public facilities and services (Koppenjan, 2005). To achieve better value for money, it transfers significant risk and the management of projects and services to the private sector (Rosenau, 2000). National Audit Office (2000) found evidence of major cost savings, while authors such as Hall (1998) are less optimistic about the supposed benefits of PPP projects. For 
example, national audit reports have frequently discovered operational problems such as the authorities' lack of experience in managing PFI contracts (NAO, 2003). PPP explores the full range of private sector management and commercial and creative skills (Rosenau, 2000). To stress these aspects of a PPP relationship, Hart (2003) had provided theoretical justifications for PPPs in terms of an incomplete contracting framework. Private participation is a natural outcome in those circumstances where it is difficult for the public sector to enter contracts due to unforeseen contingencies. Besley and Maitreesh (2001) had built on this idea and considered the responsibilities of the state and the voluntary sector in providing inputs/finance to public projects. In terms of the implementation constraints of PPP projects, a literature has now emerged that investigates the importance of coordination across functions and organisations. In this work, the focus is on the organisation and management of PPP projects (Kwak et al., 2009), including how the project should be goal oriented and should focus on results.

\section{CSFS FOR BOT PROJECTS}

The widespread use of the BOT model has promoted the development of the studies on CSFs for BOT projects by introducing different CSFs from various perspectives. Some authors are pioneers in the research on CSFs of BOT projects; for example, based on the survey on PFI projects in the UK, Li et al. (2005) summarised previous research on CSFs for PPP projects and identified the important factors that lead to success and classified them into five groups: effective procurement, ability of project implementation, government guarantee, favourable economic conditions and available financial market. In addition, as a pivotal predecessor for the private sector, Pongsiri (2002) had set up a clear regulatory framework in the PPP projects of the UK. Samii et al. (2002) focused on the dependency of related resource, commitment allocation, common goal symmetry, communication, the capability of collaboration and project culture as the key elements for project success. However, Kanter (1994) emphasised on individual excellence, importance, interdependence, investment, information communication, cooperation, institutionalisation and honesty.

Some researchers have studied CSFs for specific project types. For example, Jefferies et al. (2002) conducted research on an Australian sports stadium project and identified CSFs as a reliable consortium with a wealth of expertise, rich experience, good reputation and effective approval process and leading to improvement in the financial methods of the consortium. Their study gives public clients some suggestions on how to manage BOOT project successfully. Furthermore, various authors have reached consensus about some other CSFs with good governance acting as a crucial element in these factors (Frilet, 1997; Qiao et al., 2001). Moreover, creating a stable macroeconomic environment is very important (Qiao et al., 2001).

The success of a project calls for sound economic conditions, which constitute economic policy support (Tiong, 1996), effective financing market (Jefferies et al., 2002; McCarthy and Tiong, 1991; Qiao et al., 2001), realistic cost/ benefit evaluation (Brodie, 1995; Hambros, 1999) and good risk allocation and risk sharing in business operation (Grant, 1996). However, due to the nature of BOT and PPP projects, which is related to diverse stakeholders, including public and private, the social support (Qiao et al., 2001) is also needed and public and private sectors should take their responsibility during the project process (Kanter, 2010; Stonehouse et al., 1996). There are various studies (e.g. Gentry and Fernandez, 1997; Jefferies et al., 2002; Li et al., 2005) that claim that keeping project procurement transparent and competitive could be beneficial to achieving success.

In terms of the CSFs for BOT projects in China, the literature is limited despite the widespread use of the BOT model. The relatively early research in this field was mainly qualitative in nature. Tiong et al. (1992) introduced six CSFs (including entrepreneurial spirit, specific features in the bid, feasibility of projects, a strong team, an innovative technical skill and a sound financial plan) that help private investors negotiate and win the project contracts. These six factors exert a profound influence on the future studies. The duration of the BOT project is usually long and can be divided into several phases, including preparation, construction, operation and transfer. There is a definite linkage among these phases. Therefore, private sponsors should pay attention to the factors mentioned earlier.

Some Chinese researchers have been keen to summarise the previous studies on CSFs of BOT projects and draw on some international PPP project experiences. In this study, three significant outcomes are described, which are as follows: first, Zhang (2005) provided a comprehensive summary of CSFs for BOT projects related to similar models in different industries and in different countries. Their research extended to PFI models in the UK, toll road construction in the USA and tunnel projects in Hong Kong, which are implemented in the BOT projects' style. The fields expanded to transportation areas, including public roads, bridge, airport, port and railway and utilities sector 
involving water supply systems, waste disposal systems and telecommunication systems. This research offered a broad and comprehensive structure, which has laid a solid foundation for future study. Despite this, the list of CSFs does not give a clear definition or detailed description of each success factor, which gives rise to difficulties in deeper investigation. In contrast, Zhao et al. (2010) concentrated on BOT-type electric power projects in mainland China. According to their research, $31 \mathrm{CSFs}$ for this specific sector were identified from previous research, which they classified into five groups: feasibility of project, sound environment, strong project company, reliable contractor and good suppliers. The research conducted by Qiao et al. (2001) has exerted an impact on the study of CSFs for BOT projects. Their research integrated qualitative and quantitative methods, which included three stages: first, forming a comprehensive literature review combining unstructured interview with professional individuals' experiences from successful BOT projects based on documents, which contributed to the initial list of factors and was categorised into six phases; the second step aimed at a short list of CSFs through questionnaires and in-depth personal interviews. Consequently eight main CSFs were suggested and six phases were introduced. The last step focused on the three cases in China for demonstrating the effectiveness of CSFs' framework (Figure 3).

Figure 3. The framework for CSFs of BOT projects in China (Qiao et al., 2001). CSF = critical success factor; BOT = build-operate-transfer

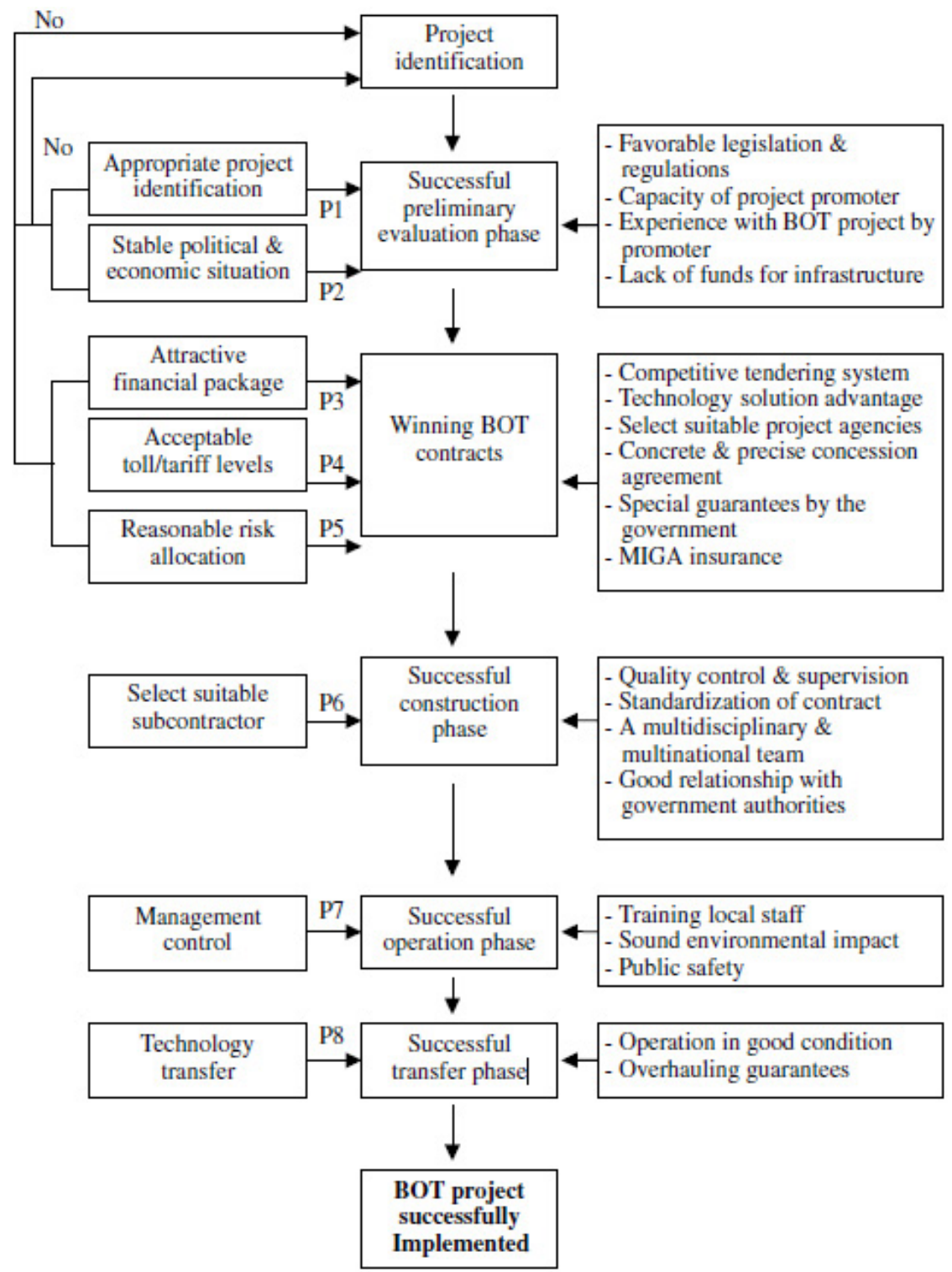


Useful findings are provided by these studies. However, there are various limitations; for instance, although many CSFs are pointed out, the relative significance of one to another cannot be ignored, and the detailed definitions on each CSF have not been provided. In view of this, many governments now employ a 'business case' methodological review framework to evaluate all BOT projects' funding proposals. The purpose of this or other similar frameworks is to provide a business rationale for the involvement of private agents in projects that are aimed at meeting the specific needs of one or more public authorities (HM Treasury, 2010). Often, these frameworks also provide parameters that examine the management implications of the private sector's involvement. In general, such methodological frameworks are meant to ensure a degree of consistency and rigour across all the review works of the BOT project. In the following, using common features of a 'business case' methodological framework, we develop a taxonomy of CSFs of the BOT project's outcomes in terms of three broad categories: risk transfer, the whole-life approach and managing partnering relationships (the extent to which the BOT project ensures timely delivery and supplies good quality assets and services) (Zhang, 2005). We argue that CSFs of the BOT project's outcomes can be better understood by identifying the linkages between different success factors. We briefly discuss these relationships in the following.

\section{Risk transfer}

PPP projects are underpinned by the need to transfer risks from the public sector to the private party managing the project. By focussing on all aspects of a project's risk, which may be related to any stage of the project, including define, build, finance and operate, it may be possible to reduce the overall risk associated with procuring new assets and services for the authority. However, risk transfer should only occur if the private sector partner is best placed to assume that risk. What is important is to make risk transfer an integral part of the BOT project's arrangement.

\section{The whole-life approach}

A corollary of adopting the risk transfer approach, as outlined earlier, is that BOT project's arrangements will need to take a long-term view of the project's outcomes. This can be seen in the way different stages of the project may be amalgamated so that responsibility for delivering the required service over the whole life of the contract is assigned to the same private sector agent, usually a consortium of companies. The underlying rationale for such an arrangement is that as the quality of the construction work is also influenced by costs such as the maintenance costs, the consortium will maintain the building to agreed standards throughout the life of the contract. There is thus an incentive for the private agent to adopt a 'whole-life' approach to construction as long-term costs can be reduced by building to higher standards.

\section{Managing partnering relationships}

Prior literature suggests that there is a specific skill set associated with the successful implementation of PPP projects (Kwak et al., 2009). For instance, management skills may be required to complete the project to budget or to ensure that the assets built or provided are of sufficient quality to remain of high standard throughout their lives. There is thus a need for the project managers to draw upon the strengths of both contracting parties. With reference to the private sector, such cooperation may also include benefitting from the private agents' entrepreneurial qualities (Kwak et al., 2009; NAO, 2003). Innovations in project organisation and management may be necessary to map out the project structure that promotes collaboration and communication. Against this background, Kwak et al. (2009) and Grant (1996) put emphasis on partnering relationships that may take the form of appointing an independent project team and an independent project leader who report to a steering committee consisting of top representatives from both the public and private sectors.

\section{RESEARCH METHODOLOGY}

This study draws on the 'business case' methodological review framework to identify and further refine the CSFs for BOT projects. The process applied can be divided into three stages: the first stage identified and summarised key CSFs for BOT/PPP projects from the literature. The initial list of CSFs proved to be complex, and some of the CSFs were repeated, which required simplification and integration. The second stage identified, from the abovementioned list, the relatively important CSFs for BOT projects in terms of the three broad PPP success factor categories (risk transfer, the whole-life approach and managing partnering relationships). Table 1 provides more parsimonious list of CSFs. 
Table 1. Refined CSF list

\begin{tabular}{|c|c|c|}
\hline No. & CSFs & Source \\
\hline CSF1 & Government support and guarantee & $\begin{array}{c}\text { Kanter (2010); Qiao et al. (2001); Stonehouse et al. (1996);Zhang et al } \\
\text { (1998) }\end{array}$ \\
\hline CSF2 & Reasonable risk allocation & Grant (1996); Qiao et al. (2001) \\
\hline CSF3 & Picking up the good project & Qiao et al. (2001) \\
\hline CSF4 & Thorough and realistic cost-benefit assessment & Brodie (1995); Hambros (1999); Qiao et al. (2001) \\
\hline CSF5 & Stable political situation & Qiao et al. (2001) \\
\hline CSF6 & A favourable legal framework & Boyfield (1992); Stein (1995); Tiong (1996) \\
\hline CSF7 & A strong project consortium & Birnie (1999); Jefferies et al. (2002); Li et al. (2005); Tiong (1996) \\
\hline CSF8 & Stable macroeconomic environment & Qiao et al. (2001); Tiong (1996) \\
\hline CSF9 & Project technical feasibility & Qiao et al. (2001); Tiong (1996); Zantke and Mangels (1999) \\
\hline CSF10 & Transparent and competitive procurement process & Gentry and Fernandez (1997); Jefferies et al. (2002);Li et al. (2005) \\
\hline CSF11 & Sound economic policy & Tiong (1996) \\
\hline CSF12 & A good contractor & Qiao et al. (2001) \\
\hline CSF13 & Multi-benefit objectives & Grant (1996) \\
\hline CSF14 & Good governance & Boyfield (1992); Stein (1995) \\
\hline CSF15 & Social support & Frilet (1997) \\
\hline CSF16 & Well-organised public agency & Li et al. (2005) \\
\hline CSF17 & Shared authority between public and private sectors & Kanter (2010); Stonehouse et al. (1996) \\
\hline CSF18 & Condition of existing infrastructure & Tiong (1996) \\
\hline CSF19 & Technology transfer & Qiao et al. (2001) \\
\hline
\end{tabular}

CSF $=$ critical success factor.

Having identified the most appropriate and relevant CSFs, a questionnaire was constructed for eliciting data from Chinese BOT project companies and relevant government departments.

\section{Survey instrument}

The questionnaire was constructed in Chinese language by a native Chinese speaker. It consisted of 19 CSFs (Table 1) based on the preliminary literature review. The majority of the questions in the survey were framed using the ordinal Likert scale. The respondents for the survey included project managers who had working experience in the BOT project companies based in mainland China and related local government workers who were in charge of BOT projects. These two groups were deemed suitable to represent the viewpoints of the private and the public sectors. Specifically, in China, the initial approval of a BOT project is normally proposed and given by the local planning authorities and various government departments take part in the project's multiple phases. Therefore, it was crucial to get a clear perspective of the government on the CSFs.

The survey targeted the provinces and municipalities, such as Hebei, Sichuan, Hunan, Guangdong, Shanghai and Beijing, where the BOT model has become the mainstream implementation approach for public infrastructure. The targeted government departments involved local governments, city development and reform bureau, energy bureau, bureau of city planning and local power bureau. For project companies, there is a long list of BOT projects in China at present, and the corresponding project companies are also published in the public domain. 
The questionnaire was pilot tested to check the reliability of research instrument, and a number of questions were removed from the research instrument and language improvements were made to the various questions to enhance consistency in respondents' understanding of the questionnaire items. E-mails were sent to 150 project managers in charge of Chinese BOT projects and 100 workers engaged in the related works for Chinese BOT projects. As a result, a total of 85 valid questionnaires were received (32 from government workers and 53 from project managers). Given web-based response rates are typically lower than surveys sent by the mail (Shih and Fan, 2008), a response rate of $34 \%$ was considered as satisfactory. It is also important to recognise that the sample was self-selected and may reflect participants' particular interest in the topic, and this may have introduced a possible element of selection bias (Couper, 2007). Questionnaire analysis shows various roles of respondents in BOT projects (Table 2), which helps to form integrated views on this issue.

Table 2. Composition of sample by respondent's role/area

\begin{tabular}{|c|c|c|c|c|c|}
\hline \multirow{2}{*}{$\begin{array}{l}\text { Public sector } \\
\text { Role/area }\end{array}$} & \multirow[b]{2}{*}{ Count } & \multirow[b]{2}{*}{ Percentage } & \multicolumn{3}{|c|}{ Private sector } \\
\hline & & & Role/Area & Count & Percentage \\
\hline Government of Sichuan Province & 4 & 12.5 & Contractor & 9 & 17.0 \\
\hline Government of Guangdong Province & 5 & 15.6 & Project manager & 11 & 20.8 \\
\hline Development Planning Commission of Hebei Province & 3 & 9.4 & Supplier & 8 & 15.1 \\
\hline Development Planning Commission of Hunan Province & 2 & 6.3 & Financier & 5 & 9.4 \\
\hline Department of Water Resources of Sichuan Province & 6 & 18.8 & Operator & 8 & 15.1 \\
\hline Department of Construction of Guangxi Province & 5 & 15.6 & Adviser & 12 & 22.6 \\
\hline $\begin{array}{l}\text { Department of Foreign Trade and Economic Cooperation } \\
\text { of Guangdong Province }\end{array}$ & 3 & 9.4 & Subtotal & 53 & 100 \\
\hline Shenzhen Municipal Government & 4 & 12.5 & & & \\
\hline Subtotal & 32 & 100 & & & \\
\hline
\end{tabular}

In addition, the composition of sample by sector is demonstrated in Table 3, including roads, tunnels and bridges in the transportation sector; power and energy sector; water and sanitary in the utilities sector and school and education facilities in the construction sector.

Table 3. Composition of sample by sector

\begin{tabular}{lcc}
\hline Project type & Count & Percentage \\
\hline \hline Power and energy & 26 & 30.6 \\
Water and sanitary & 18 & 21.2 \\
School and education facilities & 22 & 25.9 \\
Transportation & 19 & 22.4 \\
Total & 85 & 100.0 \\
\hline
\end{tabular}

\section{DATA ANALYSIS AND FINDINGS}

The data gathered were analysed using SPSS 20.0, including ranking analysis of CSFs using the relative importance index (RII) method.

\section{Reliability analysis}

To examine the internal consistency of the items in the questionnaire, Cronbach's alpha was utilised. The coefficient of Cronbach's alpha ranged from 0 to 1 , and values greater than 0.7 was normally regarded as acceptable to good (Kirkpatrick and Feeney, 2006). Most of the data in this study demonstrate Cronbach's alpha scores higher than 0.7 , 
demonstrating a good level of internal consistency.

\section{Ranking analysis}

The ranking analysis given here adopts the same method as that of Salleh's (2009), who used the relative important index in his ranking analysis on CSFs. The RIls are calculated to determine the ranking of CSFs. RII has a range from 0 to 1, and the higher value means more important the CSF is. Based on the data from 5-point Likert-type scale questionnaire survey, the calculation of RII for each factor was conducted independently.

Table 4. Reliability test results

\begin{tabular}{|c|c|c|}
\hline \multicolumn{3}{|c|}{ Cronbach's alpha reliability coefficient $=0.971$} \\
\hline No. & Corrected item: total correlation & Cronbach's alpha if item deleted \\
\hline CSF1 & 0.879 & 0.969 \\
\hline CSF2 & 0.909 & 0.968 \\
\hline CSF3 & 0.898 & 0.968 \\
\hline CSF4 & 0.906 & 0.968 \\
\hline CSF5 & 0.918 & 0.968 \\
\hline CSF6 & 0.925 & 0.967 \\
\hline CSF7 & 0.952 & 0.967 \\
\hline CSF8 & 0.934 & 0.967 \\
\hline CSF9 & 0.927 & 0.967 \\
\hline CSF10 & 0.806 & 0.969 \\
\hline CSF11 & 0.647 & 0.971 \\
\hline CSF12 & 0.912 & 0.967 \\
\hline CSF13 & 0.913 & 0.967 \\
\hline CSF14 & 0.889 & 0.968 \\
\hline CSF15 & 0.859 & 0.968 \\
\hline CSF16 & 0.802 & 0.969 \\
\hline CSF17 & 0.054 & 0.977 \\
\hline CSF18 & 0.419 & 0.973 \\
\hline CSF19 & 0.782 & 0.969 \\
\hline
\end{tabular}

$\overline{\mathrm{CSF}}=$ critical success factor.

As can be seen from Table 4, the overall value of Cronbach's alpha is 0.971 , which suggests that most of the data in this test are reliable with very high internal consistency. In addition, Table 4 also shows the values of total correlation and Cronbach's alpha if item deleted for each factor. Specifically, the value of total correlation shows the correlation between each factor and the overall reliability value, while the value of Cronbach's alpha if item deleted shows the overall reliability coefficient if the factor is not included in the calculation. Based on what Field (2009) had suggested, the factor with total correlation value less than 0.3 and/or the value of Cronbach's alpha if item deleted greater than the overall reliability coefficient ( 0.971 in this case) should be deleted because they are not correlated with overall reliability value and/or they do not contribute to the calculation of the overall reliability value. Therefore, CSF17: Shared authority between public and private sectors with a low total correlation value $(0.054)$ and a high Cronbach's alpha if item deleted value (0.977) and CSF18: Condition of existing infrastructure with a high Cronbach's alpha if item deleted value (0.973) are dropped from the list. As a result, the remaining 17 factors are further analysed (Table 5).

One can also observe from Table 5 how each CSF has been divided into three broad categories of BOT projects' success factors. There are six CSFs in the risk allocation category, six CSFs in the whole-life category and five CSFs in the project management category. These associations have been found based on a factor analysis of all CSFs along the following lines: the extent to which operating risks have been embedded into the design, build, finance and operation stages of the project; whether risk register, outline contract and payment mechanisms are consistent with the risks identified as earlier and the extent to which all stakeholders are committed to the project. For example, 
demonstrable support from all key sponsors and users is necessary for a BOT project. Such support mechanisms are built around consultations with all relevant parties. BOT projects thus ensure that all key stakeholders are involved in deciding on particular design/sustainability issues and their subsequent implementation.

Table 5. New list of CSFs after reliability test

\begin{tabular}{lc}
\hline No. & CSFs and their associations \\
\hline \hline CSF1 & Government support and guarantee: risk \\
CSF2 & Reasonable risk allocation: risk \\
CSF3 & Picking up the good project: whole life \\
CSF4 & Thorough and realistic cost-benefit assessment: whole life \\
CSF5 & Stable political situation: risk \\
CSF6 & A favourable legal framework: risk \\
CSF7 & A strong project consortium: management \\
CSF8 & Stable macroeconomic environment: risk \\
CSF9 & Project technical feasibility: whole life \\
CSF10 & and competitive procurement process: management \\
CSF11 & Sound economic policy: risk \\
CSF12 & A good contractor: management \\
CSF13 & Multi-benefit objectives: whole life \\
CSF14 & Good governance: management \\
CSF15 & Social support: whole life \\
CSF16 & Transparent \\
CSF17 & Technology transfer: whole life \\
\hline CSF = critical success factor. &
\end{tabular}

Table 6. Ranking of CSFs by RII

\begin{tabular}{|c|c|c|c|c|c|}
\hline CSFs & RII & Rank & Risk & Whole life & Management \\
\hline Reasonable risk allocation & 0.831 & 1 & $x$ & & \\
\hline Government support and guarantee & 0.806 & 2 & $x$ & & \\
\hline Picking up the good project & 0.769 & 3 & & $x$ & \\
\hline A strong project consortium & 0.700 & 6 & & & $x$ \\
\hline Project technical feasibility & 0.756 & 4 & & $x$ & \\
\hline Transparent and competitive procurement process & 0.731 & 5 & & & $x$ \\
\hline A good contractor & 0.675 & 7 & & & $x$ \\
\hline Thorough and realistic cost-benefit assessment & 0.625 & 9 & & $x$ & \\
\hline Stable political situation & 0.613 & 11 & $x$ & & \\
\hline Stable macro-economic environment & 0.619 & 10 & $x$ & & \\
\hline Sound economic policy & 0.631 & 8 & $x$ & & \\
\hline A favourable legal framework & 0.531 & 13 & $x$ & & \\
\hline Multi-benefit objectives & 0.513 & 14 & & $x$ & \\
\hline Good governance & 0.544 & 12 & & & $x$ \\
\hline Well-organised public agency & 0.513 & 15 & & & $x$ \\
\hline Technology transfer & 0.506 & 16 & & $x$ & \\
\hline Social support & 0.444 & 17 & & $x$ & \\
\hline
\end{tabular}

CSF $=$ critical success factor; $\mathrm{RII}=$ relative importance index 
As can be noted from Table 6, the overall RII values of the 17 CSFs range from 0.873 to 0.478 and the three broad categories of PPP success factors illustrate different ranking orders. In the top ten CSFs, four each belong to the 'risk factor' category and the 'whole-life' category of PPP success factors. Specifically, the findings show that 'project technical feasibility' (whole-life category) is a more significant CSF than the factor of 'a strong project consortium' (project partnership category). Similarly, the advanced technology is more crucial than whether the consortium has entrepreneurship to manage projects well. The government seems to care more about whether any technical proposals exist to provide sound solutions to the requirements for the projects. Furthermore, based on the rankings of 'stable political situation' (risk category) and 'sound economic policy' (risk category), there is more emphasis on economic aspects than the political stability. For the participants, the stable political environment is the premise guarantee for the development of projects. Without the stable political environment, BOT projects cannot be operated well despite that the economic policies are liberalised.

\section{DISCUSSION OF SURVEY FINDINGS}

In the following, we analyse all important CSFs within the general context of BOT projects' operations in China and how they perform in relation to the 'business case'-related three broad categories of BOT projects' success factors. We first focus on the most prioritised CSFs, and then briefly discuss the factors lower on the list of CSFs. In our discussion of the research's implications, we mainly focus on the government's need of using CSFs more appropriately when processing BOT projects. Where appropriate, we also briefly cover the BOT project developers' interest in adopting a more business-like approach in BOT project implementation (see, for example, the whole-life perspective section).

\section{Risk allocation}

Owing to the nature of BOT projects with a long period of time and complicated relationship, various risks would pose great threats to project entities, which exert a negative effect on risk management. First, in China, a BOT project tends to have complex networks of relationship including contractors, public agencies, suppliers, lenders, operators, government and other entities who are involved in the project agreements with project consortiums. Therefore, the reliability of these entities is important for coping with the complex relationships. For example, the creditworthiness of the Chinese project entities is difficult to guarantee, regardless of their obligations to perform (Wang et al., 2000). According to the empirical research by Wang et al. (2000), the risk from the Chinese entities' reliability tends to be the most significant factor. Therefore, a reasonable risk management system becomes a key determinant of Chinese BOT projects' success. Moreover, the long duration of BOT projects gives rise to the risks in terms of bidding, financing, constructing and operating in each phase, which calls for identifying and allocating the diverse risks at the preparing stage (Qiao et al., 2001). Thus, an effective risk allocation requires the project promoters to make a full preparation for retaining all potential risks and reallocating the risks to eliminate the negative influences.

The government's guarantee ranks very high as a factor, which is consistent with the research of Zhang et al. (1998). For example, government's guarantee was provided too late to manage risks in Shanghai YD Second Tunnel Project (Zhang et al., 1998); it was nonetheless still perceived critically important. The Shanghai government offered six main guarantees for the project developers, which contributed to an attractive package to the project investors. By contrast, some developing countries failed to recognise the importance of government's guarantees. For instance, the problems with the first BOT project (Akkuyu reactor plant project) implemented in Turkey experienced problems since the local government did not publish new restrictions on toll structure in time; it posed major threats to financial security (Barrett, 1986).

\section{The whole-life perspective}

The whole-life perspective considers whether the BOT project is affordable (or reasonably designed and priced) over the whole of its life. In the case of local authority projects, for example, this means that the project takes into account all sources of existing local authority resources, as well as additional income from capital receipts or third party income. Such a perspective underlines the need for central coordination as there may be a complementarity between different functions/operations of a BOT project. In the present case, we find evidence of the whole-life assessment and management of the asset by both the government and the developers, resulting in higher project standards. In some other cases, the main reason for higher performance delivered through BOT projects is that 
there is no partition of core and ancillary project services, enabling the private sector partner to make design and build decisions on the whole project basis.

Tiong et al. (1992) thus emphasised demonstrated and accepted need for the BOT project when foreign investors pick up their projects from the plethora of choices. They emphasised the significance of identification of good projects and provided two whole-life project-related suggestions for Chinese BOT project developers on how to select the right project. The first requirement is to identify whether there is a demonstrated and accepted need for the BOT project. Take Chinese transport facilities for instance, people are confronted with serious traffic congestion, especially at working peak hours. The best action to deal with this problem is building new roads and bridges. In this case, the demonstrated need is clear. In terms of the accepted need, it means the government attempts to tackle the problem because of its severity and they may have come up with the initial plans and cooperation with private promoters. The second requirement is project consortia can achieve near-monopoly status (so as to take a long-term whole-life perspective). In this respect, natural resources and utilities sector projects such as water and electricity tend to be more monopolistic than other types due to the distribution of natural resources. However, meeting the two requirements does not go far enough in terms of gaining the right project. For example, Tiong (1996) modified and updated his research with two further requirements in the selection method of BOT projects, namely, appropriate candidate as a privatised project and shortage of funds by local government.

\section{Project partnering relationships}

Owing to the complex and dynamic environment in China, only strong consortia have the capacity of dealing with various problems and gaining credibility of government (a developers' concern). Indeed, this trend is not restricted to China. For example, according to the survey on CSFs for PPP/PFI projects in the UK from Li et al. (2005), strength of project consortium acts as the most important factor, and generally, the winners who get the PFI contracts are large and reputable companies (Birnie, 1999).

As the foreign project companies have been constantly pouring into Chinese BOT projects' market after China joined World Trade Organization, the competition in the BOT projects' tender procedure has become increasingly tough. Thus, improving the competitive strengths is the essential strategy for the success of BOT projects. Without enough financial resources, the project consortiums cannot afford the substantial costs to develop BOT projects and technical innovation. Second, the integration and incentive system enable the consortiums to optimise their resources and make them more effective. In the view of Samii et al. (2002), efficient communication and setting common goals contribute to effective integrity of various skills and talents. In China, it is a common practice to involve a local company in the BOT projects' consortium. In this situation, consortiums should have the ability of coordinating and organising diverse entities. Furthermore, some professional and personal characteristics are also required to become a strong project consortium, such as having tenacity to overcome renewed rigour (Tiong, 1996; Turner, 1989), dealing with the tough negotiation effectively and alleviating and resolving the potential conflicts of interests among the project entities in the consortium (Pierce, 1989).

Furthermore, the factor of 'transparent and competitive procurement process' - part of the BOT management partnering relationship category - is rated as the sixth important CSF. At the early stage of the BOT model in China, most of local governments preferred direct negotiation with project promoters in the tendering process. In a direct negotiation, a high fixed rate of return is always asked by project companies with the consideration of potential risks and uncertainties, and government is likely to fall prey to manipulation (Meng et al., 2011). In addition, it is difficult to select the most appropriate project investor without a competitive procurement process. Therefore, the Chinese government has gradually adopted a competitive and transparent procurement process, which has been widely spread in the concessionaire selection (Chen and Messner, 2005). The factor of 'a good contractor' gives a similar RII as the 'transparent and competitive procurement process', again both belonging to the BOT project management category. A good contractor plays a pivotal role in the construction phase, and the success of the construction phase can directly affect the fate of the whole project. Therefore, the capabilities of the contractors exert profound influence on the success of the BOT project.

Little progress in China's BOT projects was made until State Planning Commission, Ministry of Electricity and Department of Transportation jointly issued more defined regulations on BOT projects' concession agreement in 1995 (Dikmen et al., 2008; Hambros, 1999; Wang and Tiong, 2000). Since the BOT model is still developing in China, the attitude of organisations involved in projects towards the importance of legal system varies. This has a direct effect on people's interpretations of this CSF. This study illustrates that some of the lower ranking critical factors of BOT projects in China are multi-benefit objectives, good governance, well-organised public agency, 
technology transfer and social support. Most of their rankings are consistent with previous studies (Li et al., 2005; Qiao et al., 2001).

As we have demonstrated in this study, the analysis of BOT projects in China should focus on CSFs in terms of the three broad categories of PPP success factors. In this regard, an updated list of CSFs of the top ten CSFs is given in Table 7. Although risk factors evidently play a vital role in the success of BOT projects, it is clear that the whole-life project perspective and project management partnering relationships must also be given due weight in any analysis of CSFs.

Table 7. Updated list of CSFs with top ten CSFs

\begin{tabular}{cc}
\hline No. & CSFs and their associations \\
\hline \hline CSF1 & Reasonable risk allocation: risk \\
CSF2 & Government support and guarantee: risk \\
CSF3 & A strong project consortium: management \\
CSF4 & Picking up the good project: whole life \\
CSF5 & Transparent and competitive procurement process: management \\
CSF6 & Project technical feasibility: whole life \\
CSF7 & A good contractor: management \\
CSF8 & Thorough and realistic cost-benefit assessment: whole life \\
CSF9 & Economic factors: risk \\
CSF10 & Political and legal factors: risk \\
\hline
\end{tabular}

CSF $=$ critical success factor.

\section{CONCLUSION}

The focus of this study is on creating a list of CSFs for China's BOT projects to help the Chinese government and project companies to achieve success in BOT projects. A number of observations are reported here.

First using existing summaries of CSFs for PPP/BOT projects and primary research, a refined list of CSFs with 19 factors is created. Furthermore, the CSF ranking list is produced according to the RII and their associations with three broad categories of BOT projects' success factors. Specifically, the top five important CSFs are 'reasonable risk allocation', 'government support and guarantee', 'picking up the good project', 'a strong project consortium' and 'project technical feasibility'. It is also found from the data that factors such as 'multi-benefit objectives', 'good governance', 'well-organised public agency', 'technology transfer' and 'social support' are least important for assisting to achieve BOT projects' success in China. However, some of the CSFs tend to be of different significance to the private sector compared to the public sector.

Furthermore, this study provides a comprehensive discussion on a number of CSFs in terms of their associations within three broad categories of BOT projects' success factors. What is worth mentioning is that the factors 'stable macroeconomic environment' and 'sound economic policy' are combined into one factor named 'economic factors' and the factor 'stable political situation' is combined with 'a favourable legal framework' as one factor called 'political and legal factors'. Therefore, a synthesised list of 10 CSFs is proposed by combining relevant information from the literature in terms of the three broad categories of BOT projects' success factor. It is suggested that the updated list of CSFs within this overarching framework could play a useful role in the phases of preparing, bidding, constructing, operating and transferring of BOT projects in China. Furthermore, the findings from this study may benefit other developing countries involved in major infrastructure projects. 
References

Barrett, M. (1986). 'Project finance develops new risk'. Euromoney Publications, 73: 4, http://www. euromoney.com/Article/1451705/Project-financedevelops-new-risks-construction-contractorsandproject-finance.html [Accessed 9 August 2013].

Besley, T. and Maitreesh, G. (2001). 'Government versus private ownership of public goods'. Quarterly Journal of Economics, 116: 4, 1343-1372.

Birnie, J. (1999). 'Private Finance Initiative (PFI) UK construction industry response'. Journal of Construction Procurement, 5: 1, 5-14.

Boyfield, K. (1992). 'Private sector funding of public sector infrastructure'. Public Money Management, 12: 2, 41-46.

Brodie, M.J. (1995). 'Public/private joint ventures: The government as partner - bane or benefit?'. Real Estate Issues, 20: 2, 33-39.

Chen, C. and Doloi, H. (2008). 'BOT application in China: Driving and impeding factors'. International Journal of Project Management, 26: 4, 388-398.

Chen, C. and Messner, J. (2005). 'An investigation of Chinese BOT projects in water supply: A comparative perspective'. Construction Management and Economics, 23: 9, 913-925.

Cheng, C. and Wang, Z. (2009). 'Public private partnerships in China: Making progress in a weak governance environment'. Issue, 56: 44.

Couper, M.P. (2007). 'Issues of representation in eHealth research (with a focus on web surveys)'. American Journal of Preventive Medicine, 32: 5 Suppl, 83-89.

Dikmen, I., Birgonul, M., Anac, C., Tah, J. and Aouad, G. (2008). 'Learning from risks: A tool for post-project risk assessment'. Automation in Construction, 18: 1, 42-50.

Field, A. (2009). Discovering Statistics Using SPSS. Los Angeles [i.e. Thousand Oaks, Calif.]: SAGE Publications.

Frilet, M. (1997). 'Some Universal Issues in BOT Projects for Public Infrastructure'. International Construction Law Review, 14: 4, 499-512.

Gatti, S. (2008). Project Finance in Theory and Practice. London: Elsevier/Academic Press.

Gentry, B. and Fernandez, L. (1997). 'Evolving publicprivate partnerships: General themes and urban water examples', paper presented at Proceedings of the OECD Workshop on Globalisation and the Environment: Perspectives from OECD and Dynamic Non-Member Economies, 13-14 November. Paris: p. 19-25.

Gidman, P., Blore, I., Lorentzen, J. and Schuttenbelt, P. (1995). Public-Private Partnerships in Urban
Infrastructure Services. Nairobi: UNDP/UNCHS/ World Bank-UMP, p.142.

Grant, T. (1996). 'Keys to Successful Public-Private Partnerships, Canadian Business Review'. Canadian Business Review, 23: 3, 27-28.

Hall, J. (1998). 'Private opportunity, public benefit?' Fiscal Studies, 19: 2, 121-140.

Hambros, S. (1999). Public-Private Partnerships for Highways: Experience, Structure, Financing, Applicability and Comparative Assessment: Objective Three, Final Report. [Report] Council of Deputy Ministers Responsible for Transportation and Highway Safety, Ottawa, Canada.

Hart, O. (2003). 'Incomplete contracts and public ownership: Remarks, and an application to public private partnerships'. Economic Journal, 113: 486, C69-C76.

HM Treasury. (2010) Public Private Partnerships. http:// www.hm-treasury.gov.uk/ppp_projectreview_ group.htm.

Jefferies, M., Gameson, R. and Rowlinson, S. (2002). 'Critical Success Factors of the BOOT Procurement System: Reflection from the Stadium Australia Case Study'. Engineering, Construction and Architectural Management, 9: 4, 352-361.

Kanter, R. (1994). 'Collaborative advantage: The art of alliances'. Harvard Business Review, July-August pp. 96-108.

Kanter, R. (2010). 'From spare change to real change: The social sector as beta site for business innovation'. Harvard Business Review, 77.

Kirkpatrick, L. and Feeney, B. (2006). A Simple Guide to SPSS for Windows. Belmont, CA: Thomson/ Wadsworth.

Koppenjan, J. (2005). 'The formation of public-private partnerships: Lessons from nine transport infrastructure projects in the Netherlands'. Public Administration, 83: 1, 135-157.

Kwak, Y., Chih, Y. and Ibbs, C. (2009). 'Towards a comprehensive understanding of public private partnerships for infrastructure development'. California Management Review, 51: 2, 51-78.

Li, B., Akintoye, A., Edwards, P. and Hardcastle, C. (2005). 'Critical success factors for PPP/ PFI projects in the UK construction industry'. Construction Management and Economics, 23: 5, 459-471.

McCarthy, S. and Tiong, R. (1991). 'Financial and contractual aspects of build-operate-transfer projects'. International Journal of Project Management, 9: 4, 222-227. 
Meng, X., Zhao, Q. and Shen, Q. (2011). 'Critical success factors for transfer-operate-transfer urban water supply projects in China'. Journal of Management in Engineering, 27: 4, 243-251.

NAO. (2000). Examining the Value for Money of Deals Under the Private Finance Initiative. London: National Audit Office.

NAO. (2003). Managing Resources to Deliver Better Public Services. National Audit Office. HC 61-1, Session 2003-04, London.

Pierce, R. (1989). 'Getting a BOT off the ground-the importance of the right team', paper presented at Managing BOT Project, Jakarta, Indonesia, Centre for Technology Management.

Pongsiri, N. (2002). 'Regulation and public-private partnerships'. International Journal of Public Sector Management, 15: 6, 487-495.

Public Works Financing. (1999). International Major Projects Survey. Westfield, NJ: Reinhardt Communications Corp.

Qiao, L., Wang, S., Tiong, R. and Chan, T. (2001). 'Framework for critical success factors of BOT projects in China'. The Journal of Structured Finance, 7: 1, 53-61.

Rosenau, P.V. (2000). Public-Private Policy Partnerships. Cambridge, MA: MIT.

Salleh, R. (2009). Critical Success Factors of Project Management for Brunei Construction Projects: Improving Project Performance, PhD Thesis. Queensland University of Technology.

Samii, R., Van Wassenhove, L. and Bhattacharya, S. (2002). 'An innovative public - private partnership: New approach to development'. World Development, 30: 6, 991-1008.

Schaufelberger, J. (2005). Risk Management on BuildOperate-Transfer Projects. pp. 1-10.

Shih, T., and Fan, X. (2008). 'Comparing response rates from web and mail surveys: A meta-analysis'. Field Methods, 20: 3, 249-271.

Stein, S. (1995). 'Construction financing and BOT projects'. International Business Lawyer, 23: 4, 173.
Stonehouse, J., O'Keefe, M. and Hudson, A. (1996). 'Private-public partnerships: The Toronto Hospital experience'. Canadian Business Review, 23: 2, 1720.

Tiong, R. (1996). 'CSFs in competitive tendering and negotiation model for BOT projects'. Journal of Construction Engineering and Management, 122: 3, 205-211.

Tiong, R., Yeo, K. and McCarthy, S. (1992). 'Critical success factors in winning BOT contracts'. Journal of Construction Engineering and Management, 118: 2, 217-228.

Turner, J. (1989). The history behind the Eastern Harbour Crossing. Building and Construction News, Hong Kong, Sep, pp. 17-20.

Wang, S. and Tiong, L. (2000). 'Case study of government initiatives for PRC's BOT power plant project'. International Journal of Project Management, 18: 1, 69-78.

Wang, S., Tiong, R., Ting, S. and Ashley, D. (2000). 'Evaluation and management of political risks in China's BOT projects'. Journal of Construction Engineering and Management, 126: 3, 242-250.

Zantke, G. and Mangels, B. (1999). 'Public sector client - private sector project: Transferring the state construction administration into private hands'. Engineering Construction and Architectural Management, 6: 1, 78-87.

Zhang, W., Wang, S., Tiong, R., Ting, S. and Ashley, D. (1998). 'Risk management of Shanghai's privately financed Yan'an Donglu tunnels'. Engineering, Construction and Architectural Management, 5: 4, 399-409.

Zhang, X. (2005). 'Critical success factors for public private partnerships in infrastructure development'. Journal of Construction Engineering and Management, 131: 1, 3-14.

Zhao, Z., Zuo, J., Zillante, G. and Wang, X. (2010). 'Critical success factors for BOT electric power projects in China: Thermal power versus wind power'. Renewable Energy, 35: 6, 1283-1291. 